\title{
Recombinant novel pituitary adenylate cyclase-activating polypeptide from African catfish (Clarias gariepinus) authenticates its biological function as a growth-promoting factor in low vertebrates
}

\author{
Juana Maria Lugo, Alina Rodriguez, Yusmila Helguera, Reynold Morales, Osmany Gonzalez, \\ Jannel Acosta, Vladimir Besada ${ }^{1}$, Aniel Sanchez ${ }^{1}$ and Mario Pablo Estrada \\ Animal Biotechnology Division, Aquatic Biotechnology Department and ${ }^{1}$ Physico-Chemistry Division, Center for Genetic Engineering and Biotechnology, \\ PO Box 6162, Havana 10 600, Cuba \\ (Correspondence should be addressed to M P Estrada; Email: mario.pablo@cigb.edu.cu)
}

\begin{abstract}
Nowadays, the studies of pituitary adenylate cyclase-activating polypeptide (PACAP)-related peptide (PRP) and PACAP in non-mammalian vertebrates, especially in fish, have paid attention mainly to the localization, cloning, and structural evolution of the peptides, but very little is known about its biological functions as growth-promoting factors in low vertebrates. In this work, we have cloned and characterized the PRP/PACAP cDNA from the commercially important North African catfish Clarias gariepinus. The sequence obtained agrees with the higher conservation of PACAP than of PRP peptide sequences. We have reported for the first
\end{abstract}

time the recombinant expression of fish PRP and PACAP in mammalian cells and bacteria and also demonstrated that the growth rate of fish is enhanced by both PRP and PACAP recombinant peptides. The results obtained in vivo in three different fish species, catfish (C. gariepinus), tilapia (Oreochromis niloticus), and carp (Cyprinus carpio) support the finding that PACAP rather than PRP plays a primordial role in growth control in teleost fish. This finding could help to elucidate the neuroendocrine axis proposed to explain the hypothalamic regulation of growth in non-mammalian vertebrates.

Journal of Endocrinology (2008) 197, 583-597

\section{Introduction}

Pituitary adenylate cyclase-activating polypeptide (PACAP) was first identified in the ovine hypothalamus due to its ability to stimulate cAMP formation in rat anterior pituitary cells (Miyata et al. 1989). This peptide belongs to the secretin/ glucagon superfamily of regulatory neuropeptides that also includes secretin, glucagon, glucagon-like peptides 1 and 2, vasoactive intestinal peptide, histidine-methionine peptide, histidine-isoleucine peptide, and glucose-dependent insulinotropic peptide (Campbell \& Scanes 1992).

In mammals, PACAP and growth hormone-releasing hormone (GHRH) are encoded by separate genes on separate chromosomes (Hosoya et al. 1992, Perez Jurado et al. 1994). In non-mammalian vertebrates (Parker et al. 1993, McRory et al. 1995, 1997, Alexandre et al. 2000) and protochordates (McRory \& Sherwood 1997), PACAP and GHRH-like peptide were believed to be encoded by the same gene and hence processed from the same transcript and prepropolypeptide. However, a gene encoding only GHRH in nonmammalian vertebrates was recently discovered in goldfish, zebrafish, and African clawed frog (Lee et al. 2007), and a shortened precursor cDNA encoding only for PACAP has been isolated in catfish (McRory et al. 1995), chicken
(McRory et al. 1997), and frog (Alexandre et al. 2000). Recent reports of an authentic GHRH and its receptor gene in frog and fish, based on sequence comparisons, phylogenetic studies and chromosomal localizations in vertebrates has demonstrated that the previously named GHRH-like peptides are homologs of mammalian PACAP-related peptides (PRPs). Taking this information into account, Lee et al. (2007) proposed that henceforth GHRH-like peptides be renamed as PRP.

Two molecular forms of PACAP with 38 and 27 amino acids respectively were originally isolated from sheep hypothalamus (Miyata et al. 1989, 1990). The sequence of PACAP has been remarkably well preserved from tunicate to human. In particular, the sequence of PACAP38 is identical in all mammalian species studied so far (Gonzalez et al. 1998). By contrast, PRP is moderately conserved. The high conservation of the PACAP sequence indicates that PACAP fulfils important biological functions from fish to mammals.

Studies examining the effect of PACAP on GH secretion have shown contradictory results (Montero et al. 2000). Some studies suggest that PACAP stimulates $\mathrm{GH}$ release in vitro in pituitary cells from rat (Hart et al. 1992, Jarry et al. 1992), sheep (Sawangjaroen et al. 1997), bovine (Hashizume et al. 1994), swine (Martinez-Fuentes et al. 1998), and fish (Parker et al. 1997, Montero et al. 1998, Wong et al. 1998, 2005, 
Xiao et al. 2002, Sze et al. 2007). By contrast, other studies have reported that PACAP has no effect on GH secretion (Jarry et al. 1992, Sawangjaroen \& Curlewis 1994). In vivo studies have demonstrated that PACAP increases plasma GH levels in rat (Jarry et al. 1992), but not in humans (Chiodera et al. 1996), suggesting that the GH-releasing effect of PACAP in mammals may be species-specific. The stimulatory effect of GHRH on GH secretion in mammals has been well identified (Guillemin et al. 1982, Bertherat et al. 1995); however, the presence of genuine GHRH peptides in fish was only recently demonstrated (Lee et al. 2007). This novel fish GHRH was able to stimulate $\mathrm{GH}$ secretion in fish pituitary cells in vitro (Lee et al. 2007). Additional studies are necessary to fully characterize the role of this novel neuropeptide in the $\mathrm{GH}$ regulation. On the other hand, the peptide recently renamed as a PRP has been reported to exert a weak-to-modest stimulatory effect on $\mathrm{GH}$ secretion from fish pituitary in vitro (Luo et al. 1990, Vaughan et al. 1992, Parker et al. 1997, Lee et al. 2007). In the glucagon superfamily, PRP is the only peptide whose function has remained undefined since its discovery more than a decade ago (Tam et al. 2007). Despite repeated efforts, a PRP receptor has been isolated only in goldfish (Chan et al. 1998). It is highly possible that PRP plays a physiological role in non-mammalian vertebrates, whereas its function has been lost in mammals due to the loss of its receptor in the genome (Lee et al. 2007).

To date, the studies of PRP and PACAP in non-mammalian vertebrates, especially in fish, have focused primarily on the localization, cloning, and structural evolution of these peptides and very little is yet known about their biological functions as growth factors in vivo.

In this work, we have cloned and characterized the PRP/PACAP cDNA from the commercially important African catfish (Clarias gariepinus). We have expressed both peptides in mammalian cells and bacteria, and demonstrated for the first time that both PACAP and PRP play a physiological role in growth control in teleost fish.

We have focused our study specifically to examine the possible use of recombinant PACAP as a new growthpromoting supplement in fish. Such a finding could be used as a powerful biotechnology tool to improve the fish growth in aquaculture.

\section{Materials and Methods}

\section{Animals}

African catfish (C. gariepinus) and tilapia (Oreochromis niloticus) were provided by the Mamposton Aquaculture Research Station, Havana, Cuba, and were kept alive in aerated freshwater under natural photoperiod. Water temperature was maintained between $28^{\circ} \mathrm{C}$ and $30^{\circ} \mathrm{C}$. Carp (Cyprinus carpio) were provided by Nacari Company, Havana, Cuba, and were kept as described above. All animal experiments were previously approved by the Ethics Committee of the Center for Genetic Engineering and Biotechnology, Havana, Cuba.

\section{Cell cultures}

Baby hamster kidney-21 cells (BHK; ATCC CRL-8544) were cultured in Dulbecco's modified Eagle's medium (DMEM; Gibco) and were maintained in an agitated cultivation system at $5 \% \mathrm{CO}_{2}$ atmosphere with a relative humidity of $95 \%$. The cells were cultivated every $3-4$ days at a seeding density of $2 \cdot 5 \times 10^{5}$ cells $/ \mathrm{ml}$.

\section{Primer designs}

The specific primers used to amplify the C. gariepinus cDNA corresponding to PRP/PACAP (PAC) were F-PRP/PAC and $\mathrm{R}-\mathrm{PRP} / \mathrm{PAC}$ based on Ictalurus punctatus PRP/PACAP cDNA (GenBank accession number AF321243). Primers for signal peptide-PRP (SP-PRP) to be cloned into mammalian expression vector pTargeT (Promega) were F-PRP/PAC and $\mathrm{R}-\mathrm{CMV}-\mathrm{PRP}$; for PACAP without signal peptide to be cloned into pTarge $\mathrm{T}$ vector were F-CMV-PACAP and R-CMVPACAP; for SP-PRP to be cloned immediately adjacent to the 5'-PACAP region were F-SP and R-SP; and for PACAP to be cloned into Escherichia coli expression vector pTYB1 (New England Biolabs, USA) were F-pTYB-PRP, R-pTYB-PRP, F-CMV-PACAP, and R-pTYB-PACAP. The specific primers (F- $\beta$-actin and $\mathrm{R}$ - $\beta$-actin), based on tilapia (Oreochromis mossambicus) $\beta$-actin sequence (GenBank accession number $\mathrm{AB} 037865)$, were used to verify the quality of synthesized cDNAs. The primer sequences with the restriction endonuclease sites included for the cloning are given in Table 1.

\section{$R N A$ isolation}

Total RNA from C. gariepinus brain was extracted using RNAgents total RNA isolation system (promega) and was quantified by measuring the absorbance at $260 \mathrm{~nm}$ and stored at $-80{ }^{\circ} \mathrm{C}$ until use.

\section{Isolation of $c D N A$ encoding $\mathrm{C}$. gariepinus $P R P / P A C A P$ precursor}

Five micrograms of total RNA from C. gariepinus brain and $1 \mu \mathrm{l}$ oligo $(\mathrm{dT})_{15}(0.5 \mu \mathrm{g} / \mu \mathrm{l})$ were incubated at $70{ }^{\circ} \mathrm{C}$ for $5 \mathrm{~min}$ and placed on ice. The reaction was carried out in a total volume of $20 \mu \mathrm{l}$ with $1 \times$ avian myeloblastosis virus (AMV)-reverse transcriptase (RT) buffer, $1 \mu \mathrm{M}$ of each dNTP, $1 \mathrm{u} / \mu \mathrm{l}$ RNase inhibitor, and $15 \mathrm{u} / \mu \mathrm{g}$ AMV-RT (Promega); incubated at $42{ }^{\circ} \mathrm{C}$ for $30 \mathrm{~min}$ and at $95^{\circ} \mathrm{C}$ for $5 \mathrm{~min}$; and then diluted to a final volume of $100 \mu \mathrm{l}$ in nuclease-free water. The quality of synthesized cDNA was evaluated by PCR amplification of $C$. gariepinus $\beta$-actin partial cDNA using the specific primers F- $\beta$-actin and $\mathrm{R}-\boldsymbol{\beta}$ actin (Table 1). The PCRs were carried out using $20 \mu$ five times diluted RT mixture, the appropriate PCR buffer volume at a final concentration of $1 \times(100 \mathrm{mM}$ Tris- $\mathrm{HCl}$, $500 \mathrm{mM} \mathrm{KCl}$ (pH 8.3), 1.5 mM $\mathrm{MgCl}_{2}$ ), 50 pmol of each primer based on the I. punctatus PRP/PACAP cDNA 
Table 1 Primer sequences

Primer sequence $^{\mathrm{a}}$
Primer name
F-PRP/PAC
R-PRP/PAC
R-CMV-PRP
F-CMV-PAC
R-CMV-PAC
F-SP
R-SP
F-pTYB-PRP
R-pTYB-PRP
R-pTYB-PAC
F- $\beta$-actin
R- $\beta$-actin

$5^{\prime}$-gcagccatggccaaatctagtagagctac- $3^{\prime}$

$5^{\prime}$-ggaattcctttaatggcttgacttcgtacat- $3^{\prime}$

$5^{\prime}$-cgggatccttacgacagtggctccgagtcttcc- $3^{\prime b}$

$5^{\prime}$-catc catatgcactcggacggcattttcacgg- $3^{\prime}$

$5^{\prime}$-cgggatccttatttgtttctaaacctctgtctgtacct- $3^{\prime}$

$5^{\prime}$-ctagctag $\overline{c a t g g c c a a a t c t a g t a g a g c t a c-3 '}$

$5^{\prime}$-gtttcggctcttctctcggg- $3^{\prime}$

$5^{\prime}$-catc catatgcatgcagacggattgttagatagag- $3^{\prime}$

$5^{\prime}$-tgctcttccgcacgacagtggctccgagtcctct- $3^{\prime}$

$5^{\prime}$ - tgctcttcc gcatttgtttctaaacctctgtctgtacct- $3^{\prime}$

$5^{\prime}$-acactgtgcccatctacgaggg- $3^{\prime}$

$5^{\prime}$-cgatccagacggagtatttacgc- $3^{\prime}$
Restriction endonuclease enzyme

Ncol
EcoRI
BamHI
Ndel
BamHI
Nhel
c $^{-}$
Ndel
Sapl
Sapl
c
C $^{c}$

${ }^{\mathrm{a}}$ Restriction endonuclease sites are in bold.

${ }^{\mathrm{b}}$ The triplet codon is indicated with a single underline.

${ }^{c}$ Primers without restriction endonuclease site.

sequence, and 2.5 units of Taq DNA polymerase (Heber Biotec SA, Havana, Cuba). The amplification of C. gariepinus PRP/PACAP cDNA was carried out for 30 cycles as follows: denaturation for $30 \mathrm{~s}$ at $95^{\circ} \mathrm{C}, 1 \mathrm{~min}$ annealing at $68^{\circ} \mathrm{C}$, and 1 min extension at $72{ }^{\circ} \mathrm{C}$, followed by an initial denaturation at $95^{\circ} \mathrm{C}$ for $5 \mathrm{~min}$. Amplification was completed with an additional extension step at $72{ }^{\circ} \mathrm{C}$ for $5 \mathrm{~min}$. The PCR products were analyzed in $1.5 \%$ agarose gel electrophoresis.

\section{Cloning of the PRP and PACAP $c D N A$ into mammalian expression vectors}

The sequence containing both the signal peptide and mature $\mathrm{PRP}$ was isolated by PCR using the C. gariepinus PRP/PACAP cDNA precursor as template. The cDNA encoding only for the mature PACAP was also amplified as described above. The signal peptide sequence from $C$. gariepinus PRP/PACAP precursor was amplified and cloned into pTarge $T$ expression vector (Promega) immediately adjacent to the 5'-PACAP region. The specific primers F-PRP/PAC, R-CMV-PRP, F-CMV-PACAP, and R-CMV-PACAP were used in order to amplify the SP-PRP and PACAP cDNA sequences respectively, and to include the restriction endonuclease sites necessary for cloning into the eukaryotic expression vector pTargeT (Table 1). The signal peptide amplification for SP-PACAP vector construction was done using the F-SP and R-SP primers (Table 1). The final vectors (pCMV-SP-PRP and pCMVSP-PACAP) were tested for both restriction endonuclease site analysis and DNA sequencing.

\section{Sequence analysis}

The plasmid DNAs were purified using a Mini Preps kit (Promega), and the inserts were completely sequenced by Macrogen (Seoul, South Korea) using the specific primers annealing to the regions of the vector flanking the multiple cloning sites.
Sequence analysis was carried out using BLASTX (http:// www.ncbi.nlm.nih.gov/blast/blastx) or CLUSTALW (http://www.ebi.ac.uk/Tools/clustalw).

\section{Transfection of $\mathrm{BHK}-21$ cells}

BHK-21 cells were transfected with the pCMV-SP-PRP and pCMV-SP-PACAP vectors, previously linearized with BamHI restriction enzyme, using a stock solution of linear $25 \mathrm{kDa}$ polyethylenimine (PEI; Aldrich). The PEI transfection agent was prepared in water at a final concentration of $1 \mathrm{mg} / \mathrm{ml}$ and the $\mathrm{pH}$ adjusted to $6 \cdot 8$ with $\mathrm{HCl}$. This solution was sterilized using a $0 \cdot 22 \mu \mathrm{m}$ filter and stored at $-80^{\circ} \mathrm{C}$ until use.

Typically, $1.5 \times 10^{6}$ cells in DMEM were plated onto a $100 \mathrm{~mm}$ dish, 1 day prior to the transfection. For transfecting, the cells were washed once with DMEM, suspended in the same medium at $1 \times 10^{6}$ to $2 \times 10^{6}$ cells $/ \mathrm{ml}$ and then dispensed into 12 -well plates $(1 \mathrm{ml})$. Meanwhile, $7 \mu \mathrm{g}$ of each vector DNA and $500 \mathrm{ng}$ pCMV-GFP (the green fluorescent protein DNA sequence cloned previously into pTarge T vector) in $150 \mathrm{mM} \mathrm{NaCl}$ were mixed with PEI at a 1:1 ratio and incubated at room temperature for $10 \mathrm{~min}$. The DNA-PEI mix was added to each well and the plates incubated for $4 \mathrm{~h}$ at $37^{\circ} \mathrm{C}, 5 \% \mathrm{CO}_{2}$ atmosphere, and $95 \%$ humidity. Following this the cells were diluted with $1 \mathrm{ml}$ DMEM and incubated for $48 \mathrm{~h}$. The transfected cells were harvested by trypsinization with a solution containing $0 \cdot 05 \%$ trypsin and $0.53 \mathrm{mM}$ EDTA in Hanks' balanced salt solution (Gibco, Invitrogen). The trypsinization was stopped by adding DMEM supplemented with 10\% inactivated horse serum (Sigma). The harvested cells were washed three times with $1 \mathrm{ml}$ Hanks' balanced salt solution and then frozen in liquid nitrogen until use.

The co-transfection of the pCMV-GFP plasmid with each of the DNA vectors, as described above, was used to evaluate the transfection efficiency. Untransfected as well as pTarge T 
vector-transfected plates (mock-transfected cells) were used as negative controls.

\section{Static hemipituitary gland culture}

A sample of juvenile tilapias (O. niloticus) was randomly taken from the tank in the morning prior to feeding (0830-1030 h). After anesthetizing with the methanesulfonate salt of 3 -aminobenzoic acid ethyl ester (Sigma) dissolved in water, pituitary glands were immediately removed and placed in an ice-cold saline solution $(4 \cdot 17 \mathrm{mM} \mathrm{NaHCO} 3,0 \cdot 1 \% \mathrm{BSA}(\mathrm{pH}$ $7 \cdot 5$ ), diluted to $80 \%$ ). Afterward, individual pituitary glands were dissected along the sagittal axis into two equal parts. The hemipituitaries were then rinsed three times in the $80 \%$ saline solution described above, placed individually into single wells of 24-well tissue culture plates (Corning Costar, Corning, NY, USA), and cultured in $1 \mathrm{ml} 80 \%$ saline solution for $1 \mathrm{~h}$ at $30{ }^{\circ} \mathrm{C}$ on a shaker platform. The medium was then replaced with $1 \mathrm{ml} \mathrm{M199}$ (Gibco; supplemented with $4.17 \mathrm{mM}$ $\mathrm{NaHCO}_{3}, 25 \mathrm{mM}$ HEPES, 0.1\% BSA, $0.7 \mathrm{mM}$ L-glutamine, $100 \mu \mathrm{g} / \mathrm{ml}$ streptomycin, $100 \mathrm{u} / \mathrm{ml}$ penicillin-G ( $\mathrm{pH} 7 \cdot 5$ ), and $5 \%$ inactivated horse serum), and incubated for $4 \mathrm{~h}$ at $30{ }^{\circ} \mathrm{C}$ to establish basal $\mathrm{GH}$ release. Prior to the assays, the medium was replaced with either supplemented M199 (control wells) or supplemented M199 containing the test substance (treatment wells), but both without serum. Treatments consisted of adding equal volume $(300 \mu \mathrm{l})$ of the culture supernatants of the pCMV-SP-PRP-, pCMVSP-PACAP-, and pTargeT-transfected BHK-21 cells. The synthetic GH secretagogue (GHRP-6; Lipotec, Barcelona, Spain) was also included as positive control. The medium was removed after 24 and $48 \mathrm{~h}$ of incubation and stored at $-20{ }^{\circ} \mathrm{C}$ prior to $\mathrm{GH}$ assays. Treatments were tested in duplicate, using three to four fish pituitaries for each test. This experiment was repeated at least two times.

\section{GH assays}

The GH secreted in vitro was measured using a noncompetitive ELISA. The 96-well MaxiSorp plates (Nalge Nunc International, Roskilde, Denmark) were coated $3 \mathrm{~h}$ at $37^{\circ} \mathrm{C}$ with anti-tilapia $\mathrm{GH}$ monoclonal antibody 1 (tiGH1 $\mathrm{mAb}$; CIGB, Cuba) at $10 \mu \mathrm{g} / \mathrm{ml}$ in $0.05 \mathrm{M}$ carbonate buffer ( $\mathrm{pH} 9 \cdot 6,100 \mu \mathrm{l} /$ well). The plates were washed two times with PBS-T (137 mM NaCl, $2.7 \mathrm{mM} \mathrm{KCl}, 4.3 \mathrm{mM} \mathrm{Na}_{2}$ $\mathrm{HPO}_{4} \cdot 7 \mathrm{H}_{2} \mathrm{O}$, and $0 \cdot 05 \%$ Tween $\left.20(\mathrm{pH} 7 \cdot 3)\right)$ and blocked with $3 \%$ skim milk (Oxoid, Cambridge, UK) in PBS $1 \times$ (200 $\mu \mathrm{l} /$ well) by $1 \mathrm{~h}$ at $37^{\circ} \mathrm{C}$. A standard tilapia GH curve in the range of $32-0.5 \mathrm{ng} / \mathrm{ml}$ was obtained by twofold dilutions in $0.5 \%$ skim milk in PBS $1 \times$ and it was dispensed by duplicate in the same plate. Test samples were diluted at a ratio of 1:2 as described above and were incubated on the plates overnight at $4{ }^{\circ} \mathrm{C}$. After washing the plates for four times with PBS-T, $100 \mu \mathrm{l}$ horseradish peroxidase (HRP)-tiGH2 mAb conjugate (CIGB), diluted at a ratio of 1:15 000 in PBS $1 \times$, containing $0 \cdot 5 \%$ skim milk were added to each well. The plates were incubated for $1 \mathrm{~h}$ at $37^{\circ} \mathrm{C}$ and then washed eight times with PBS-T. Then the substrate buffer $(0 \cdot 2 \mathrm{M}$ $\mathrm{Na}_{2} \mathrm{HPO}_{4}, \quad 0 \cdot 1 \mathrm{M}$ citric acid $(\mathrm{pH} 5.0)$ ) containing $0.5 \mathrm{mg} / \mathrm{ml}$ ortho-phenylenediamine and $5 \mu \mathrm{l} \quad 30 \% \quad \mathrm{H}_{2} \mathrm{O}_{2}$ were added $(100 \mu \mathrm{l} /$ well). The reaction was stopped $15 \mathrm{~min}$ later by adding $50 \mu \mathrm{l}$ per well $2.5 \mathrm{M}$ sulfuric acid. The absorbance was measured at $492 \mathrm{~nm}$ using the Titertek Multiskan Plus spectrophotometer.

Cloning of the PRP and PACAP $c D N A$ into E. coli expression vectors

The mature PRP and PACAP cDNA sequences amplified by PCR using the PRP/PACAP cDNA precursor as template and the specific primers F-pTYB-PRP, R-pTYB-PRP, F-CMV-PACAP, and R-pTYB-PACAP respectively (Table 1), were subcloned into pGEM-T Easy vector using the pGEM-T Easy vector system I kit (Promega). After double digestion with NdeI and SapI, the purified DNA fragments were directly ligated to NdeI/SapI double digested pTYB1 expression vector. The pTYB vectors are commonly used for cloning and the expression of recombinant proteins in E. coli. The pTYB1 is a C-terminal fusion vector in which the C-terminus of the target protein is fused to the intein tag. This vector is part of the Intein-Mediated Purification with an Affinity Chitin-Binding Tag (IMPACT) system (New England Biolabs, Beverly, MA, USA). The insertion of the PRP and PACAP genes into the pTYB1 vector (pTYB1PRP and $p$ TYB1-PACAP) was verified by both restriction endonuclease sites analysis and DNA sequencing.

\section{Expression of the recombinant mature $P R P$ and $P A C A P$ in bacteria}

The pTYB1 vector uses a T7 promoter-driven system to achieve high levels of expression and tight transcriptional control in E. coli. The pTYB1-PRP and pTYB1-PACAP recombinant plasmids were transformed into electrocompetent E. coli strain BL21 harboring the $\lambda$ DE3 lysogen that carries the T7 RNA polymerase under the control of the lac UV5 promoter. Five milliliters of Luria-Bertani (LB) medium containing $50 \mu \mathrm{g} / \mathrm{ml}$ ampicillin were inoculated with one colony and grown overnight at $37^{\circ} \mathrm{C}$ with vigorous shaking. This culture was used to inoculate $11 \mathrm{LB}$ medium containing $50 \mu \mathrm{g} / \mathrm{ml}$ ampicillin. The expression of the recombinant PRP and PACAP was induced at an optical density $(600 \mathrm{~nm})$ of 0.5 by adding $0.5 \mathrm{mM}$ isopropyl- $\beta$-Dthiogalactopyranoside (IPTG) and grown for $5 \mathrm{~h}$. After induction, the cells were harvested by centrifugation at $5000 \boldsymbol{g}$ for $20 \mathrm{~min}$ and stored frozen until use. The cell pellet was thawed and resuspended in lysis buffer $(20 \mathrm{mM}$ Tris- $\mathrm{HCl}$ (pH 8), $500 \mathrm{mM} \mathrm{NaCl}, 1 \mathrm{mM}$ EDTA, $20 \mu \mathrm{M}$ phenylmethylsulfonyl fluoride). A French press was used to lyse the cells. The expression of the fusion proteins was tested by both $10 \%$ SDS-PAGE and western blot analysis. Because the pTYB vectors (New England Biolabs) are not recommended as 
control for testing expression, the intact polylinker region apparently causes poor expression and the control plasmid pMYB5 was used. This control plasmid carries the E. coli malE gene encoding the maltose-binding protein $(42 \mathrm{kDa})$ fused in-frame to the coding region of the intein tag.

To induce cleavage of the PRP and PACAP from the intein fusion protein, the supernatants obtained by lysate centrifugation were incubated overnight at $4{ }^{\circ} \mathrm{C}$ with $50 \mathrm{mM}$ cysteine solution ( $\mathrm{pH} 9$ ). Afterward, the supernatants were clarified by centrifugation at $10000 \boldsymbol{g}$ for $30 \mathrm{~min}$, dialyzed overnight at $4{ }^{\circ} \mathrm{C}$ against PBS $1 \times$, and stored at $-20{ }^{\circ} \mathrm{C}$ until use. The cleavage proteins were checked by both $(16.5 \%$ T/3\% C) Tricine-SDS-PAGE (Schagger \& von Jagow 1987) and mass spectrometry (MS). The quantity of cleavage peptide from intein was estimated by comparison with recombinant epidermal growth factor standards (CIGB) in the Tris-Tricine gel.

\section{Protein analysis}

Protein concentrations in the clarified lysate of the catfish PRP- and PACAP-transfected E. coli BL21 (D3) cells were determined using the BCA Protein Assay kit (Pierce, Rockford, IL, USA), according to the manufacturer's instructions. The purity level of the PRP and PACAP cleaved from the intein was estimated as the percentage of each peptide versus total proteins in the appropriate lane of the Tris-Tricine gel stained with Coomassie blue (Bio-Rad). The digital gel images used in these analyses were obtained using a Hewlett-Packard Scanjet Plus. Data were processed with Molecular Analyst software version 1.4.1 (Bio-Rad).

\section{Western blot analysis}

To verify the PRP and PACAP expression as an intein-tagged fusion protein, western blot analyses were carried out. The fused PRP and PACAP proteins were electrophoretically fractionated by $10 \%$ SDS-PAGE and transferred to a nitrocellulose membrane. After blocking with 5\% skim milk (Oxoid) in PBS $1 \times$, the membrane was incubated for $2 \mathrm{~h}$ at room temperature with the rabbit serum raised against a peptide derived from the Bacillus circulans chitin-binding domain (New England Biolabs). After washing with PBS-T once and with PBS $1 \times$ twice, the membrane was incubated with a 1:5000 dilution of anti-rabbit polyclonal antibody HRP conjugate (Amersham Biosciences), as secondary antibody with gently shaking for $1 \mathrm{~h}$ at room temperature (RT). The detection was carried out using chemiluminescence with the ECL Western blotting Analysis System (Amersham Biosciences) according to the manufacturer's instructions.

\section{Mass spectrometric analysis of the recombinant PRP and PACAP}

Specific bands were incised from Coomassie blue-stained Tris-Tricine gels. These bands were washed with $200 \mathrm{mM}$ $\mathrm{NH}_{4} \mathrm{HCO}_{3}$ in $50 \%$ acetonitrile. After the dehydration of the gels, PRP was digested with trypsin and PACAP with lysyl endopeptidase in $50 \mathrm{mM} \mathrm{NH} \mathrm{HCO}_{3}$ overnight at $37^{\circ} \mathrm{C}$. Derived peptides were eluted and desalted (Gonzalez et al. 2003). The ESI-MS spectra were acquired using a QTof-2 (Micromass, Manchester, UK) fitted with a Z-spray nanoflow electrospray ion source operated at $80{ }^{\circ} \mathrm{C}$ with a drying gas flow at $50 \mathrm{l} / \mathrm{h}$. The peptides eluted from ZipTips with $60 \%$ acetonitrile in 1\% formic acid (Millipore, Billerica, MA, USA) were loaded into borosilicate nanoflow tips and submitted to $900 \mathrm{~V}$ and $35 \mathrm{~V}$ of capillary and cone voltage respectively. To acquire the ESI-MS/MS spectra, the first quadrupole was used to select the precursor ion within a window of $\sim 2 \mathrm{Th}$. Argon was used in the collision chamber at $\sim 3 \times 10^{-2}$ Pa pressure and collision energies between 23 and $45 \mathrm{eV}$ were set to fragment precursor ions. Data acquisition and processing were performed using MassLynx v3.5 (Micromass). Sequence tags were manually extracted and used to identify the proteins by the PepSea program (http:// pepsea.protana.com/PA_PeptidePatternForm.html).

Growth-promoting effect of the recombinant PRP and PACAP in fish larvae treated by immersion baths

The growth promotion experiments were performed in C. gariepinus larvae $0 \cdot 020 \pm 0 \cdot 007 \mathrm{~g}$ in weight and $1 \cdot 215 \pm$ $0.128 \mathrm{~cm}$ in length $(n=200)$, in O. niloticus larvae $0.133 \pm$ $0.054 \mathrm{~g}$ in weight and $1.537 \pm 0.246 \mathrm{~cm}$ in length $(n=150)$, and in Carp (Cyprinus sp.) larvae 0.018 $\pm 0.005 \mathrm{~g}$ in weight and $1 \cdot 203 \pm 0 \cdot 132 \mathrm{~cm}$ in length $(n=450)$. Each experiment took place independently. In each assay, the groups were acclimated in 801 tanks containing running freshwater for 1 week prior to the experiment. The fish were fed to satiation with a basal diet twice a day. Prior to treatment, the tanks were cleaned using a siphon and the amount of water was decreased to 21 . Then, $10 \mathrm{ml}$ semi-purified recombinant PRP or PACAP, as described above, were added in a quantity equivalent to $400 \mu \mathrm{g}$ of each peptide. Each treatment was carried out for $90 \mathrm{~min}$ without water recirculation. The treatment was repeated three times a week for 4 weeks. In each experiment, one group was included as negative control. This control group received the clarified supernatant of lysis cells transformed with pTYB1 containing equivalent amounts of $E$. coli proteins to the PRP and PACAP treatments. In the experiment with $C$. gariepinus larvae, another control group did not receive any treatment to determine if there was any consequence of the immersion bath procedure in growth performance. Growth-promoting effects were evaluated by the increase in body weight and length. Data were expressed as mean \pm s.D.

\section{Skin pigmentation evaluation}

Fish skin pigmentation was determined by visual evaluation and photography at the end of the experiment. A total of 150 carp were analyzed. The presence of red, green, or both pigments was taken into account in this study. Data were 
illustrated as the percentage of the total fish that showed red, green, or both skin pigments.

\section{Statistical analysis}

The statistical analyses were carried out using GraphPad Prism statistical Software Inc., version 4.00.255 (San Diego, CA, USA). The normality of the data was evaluated using Barlett test $\left(\chi^{2}\right)$. Data were also evaluated using one-way ANOVA. Data with normal distribution and equal variances were analyzed using Newman-Keuls multiple comparison test. Data with unequal variances were analyzed by the Kruskal-Wallis test followed by Dunn's multiple comparison post-test. Treatments were considered to be significantly different if $P<0 \cdot 05$.

\section{Results}

Isolation of the $\mathrm{CDNA}$ precursor encoding $\mathrm{C}$. gariepinus $P R P / P A C A P$

A 728 bp cDNA precursor encoding both PRP and PACAP was isolated from the brain of the African catfish (C. gariepinus) by RT-PCR using specific primers based on the I. punctatus sequence (Fig. 1). The obtained cDNA consisted of the signal peptide from 1 to $60 \mathrm{bp}$ (aa 1-20), a cryptic peptide, PRP region from 250 to $384 \mathrm{bp}$ (aa 84-129), PACAP from 391 to 504 bp (aa 131-169), and the $3^{\prime}$-untranslated region (Fig. 2).

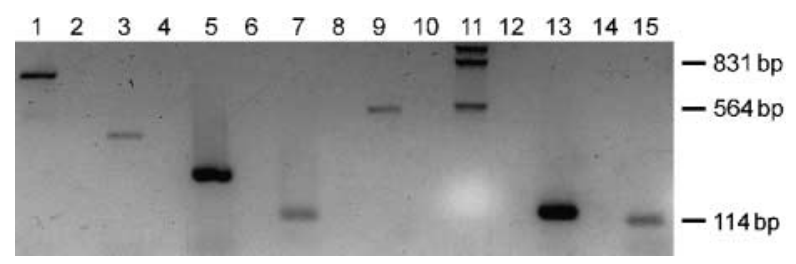

Figure 1 Electrophoresis in $1 \cdot 5 \%$ agarose gel that shows the cDNAs encoding C. gariepinus PRP/PACAP, PRP, and PACAP. Lane 1: RT-PCR to amplify the PRP/PACAP CDNA precursor from the brain of the African catfish (C. gariepinus). Lane 3: PCR to amplify the cDNA sequence encoding for both signal peptide from PRP/PACAP precursor and PRP with the restriction endonuclease sites to be cloned into pTargeT vector (Promega). Lanes 5 and 7: PCRs to amplify the signal peptide from PRP/PACAP precursor and PACAP sequences respectively, with the restriction endonuclease sites in the correct open reading frame for cloning both into pTargeT vector. Lane 9: positive control RT-PCR using brain total RNA from C. gariepinus as template and $\beta$-actin-specific primers based on O. mossambicus $\beta$-actin cDNA. Lane 11: Fragments of the molecular weight marker $\lambda$ HindIII/EcoRI (HeberBiotec, SA). Lanes 13 and 15: PCRs to amplify the PRP and PACAP cDNAs respectively, with the restriction endonuclease sites necessary for cloning into the pTYB1 bacterial expression vector (New England Biolabs, USA). Lanes 2, 4, 6, 8, 10, 12 and 14: negative control PCRs (without template) with respect to lanes $1,3,5,7,9,13$ and 15 respectively. For PRP and PACAP cDNA amplifications, the PRP/PACAP cDNA precursor was used as template.
The organization of the C. gariepinus PRP/PACAP polypeptide is very similar to other catfish (McRory et al. 1995, Small \& Nonneman 2001). PACAP is preceded by a dibasic amino acid enzyme-processing site, lysine-arginine, and is followed by a glycine-arginine-arginine-processing site that would yield a 38 amino acid peptide with an amidated C-terminus. Processing at the second amidation site within the PACAP sequence would result in the 27 amino acid PACAP.

Comparison of the C. gariepinus PACAP38 sequence with other PACAP sequences in fish showed more than $90 \%$ identity (Fig. 3). In general, the deduced amino acid sequence of the C. gariepinus PACAP was highly homologous (more than $80 \%$ identity) to sequences previously identified from tunicates to mammalians (Fig. 3). The PRP sequence was less conserved between fish and higher vertebrates. For example, C. gariepinus PRP shared only 35\% identity with Homo sapiens PRP. The sequence of PRP is only somewhat conserved among closely related species.

\section{Transient expression of the mature PRP and PACAP in mammalian cells}

The sequences encoding mature forms of C. gariepinus PRP and PACAP were accurately amplified by PCR for cloning into the eukaryotic expression vector p TargeT (Fig. 1). In both cases, the signal peptide corresponding to the $C$. gariepinus PRP/PACAP precursor was used to direct the expressed target proteins to the $\mathrm{BHK}-21$ culture supernatant. The co-transfection of the pCMV-GFP plasmid with each of the DNA vector constructs enabled transfection normalization by microscopic evaluation at the end of the experiment (data not shown).

\section{GH in vitro assays using hemipituitary gland culture}

A statistically significant increase in the $\mathrm{GH}$ secretion was observed when the pituitary glands were treated for 24 and $48 \mathrm{~h}$ with equal supernatant quantities of the PRP- or PACAP-transfected BHK-21 cells $(P<0 \cdot 05)$ (Table 2$)$. Dosedependent increases in $\mathrm{GH}$ secretion were observed when the pituitary glands were treated with GHRP-6 as positive control up to $5 \mu \mathrm{g}$ / pituitary gland $(6 \mathrm{nM})$. At $10 \mu \mathrm{g} /$ pituitary gland (12 nM), an inhibition response was observed (Table 2).

\section{Recombinant expression of $\mathrm{C}$. gariepinus $P R P$} and PACAP in E. coli

The mature forms of the C. gariepinus PRP and PACAP were amplified by PCR to be cloned into the pTYB1 expression vector. In both cases, the expected size of $135 \mathrm{bp}$ (PRP) and $114 \mathrm{bp}$ (PACAP) were obtained (Fig. 1). The correct insertion of the target cDNAs into pTYB1 vector was corroborated through restriction endonuclease site and DNA sequencing analysis.

Expression analysis of the PRP and PACAP as intein tags by SDS-PAGE showed bands of the estimated $60 \mathrm{kDa}$ size in the 


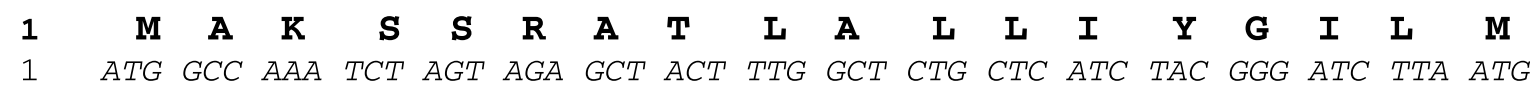

$\begin{array}{lllllllllllllllllll}19 & \mathbf{R} & \mathbf{Y} & \mathbf{S} & \mathbf{A} & \mathbf{Q} & \mathbf{C} & \mathbf{T} & \mathbf{P} & \mathbf{I} & \mathbf{G} & \mathbf{M} & \mathbf{G} & \mathbf{F} & \mathbf{P} & \mathbf{N} & \mathbf{M} & \mathbf{R} & \mathbf{L}\end{array}$

55 CGC TAC AGC GCC CAA TGC ACA CCC ATC GGA ATG GGC TTC CCC AAT ATG AGG CTA

$\begin{array}{lllllllllllllllllll}37 & \mathbf{E} & \mathbf{N} & \mathbf{D} & \mathbf{V} & \mathbf{F} & \mathbf{G} & \mathbf{D} & \mathbf{E} & \mathbf{G} & \mathbf{N} & \mathbf{S} & \mathbf{L} & \mathbf{S} & \mathbf{E} & \mathbf{L} & \mathbf{S} & \mathbf{Y} & \mathbf{E}\end{array}$

109 GAA AAC GAC GTG TTC GGG GAC GAg GGA AAC TCG TTA Agt GAg CTG TCC TAC GAG

$\begin{array}{llllllllllllllllllll}55 & \mathbf{P} & \mathbf{D} & \mathbf{T} & \mathbf{M} & \mathbf{S} & \mathbf{A} & \mathbf{R} & \mathbf{S} & \mathbf{A} & \mathbf{P} & \mathbf{A} & \mathbf{L} & \mathbf{P} & \mathbf{E} & \mathbf{D} & \mathbf{A} & \mathbf{Y} & \mathbf{T}\end{array}$

163 CCG GAC ACG ATg AGC GCG CGC AGT GCT CCA GCC CTC CCT GAA GAC GCA TAC ACA

$\begin{array}{lllllllllllllllllll}73 & \mathbf{L} & \mathbf{Y} & \mathbf{Y} & \mathbf{P} & \mathbf{P} & \mathbf{E} & \mathbf{R} & \mathbf{R} & \mathbf{A} & \mathbf{E} & \mathbf{T} & \mathbf{H} & \mathbf{A} & \mathbf{D} & \mathbf{G} & \mathbf{L} & \mathbf{L} & \mathbf{D}\end{array}$

217 CTG TAC TAC CCG CCC GAG AGA AGA GCC GAA ACG CAT GCA GAC GGA TTG TTA GAT

$\begin{array}{lllllllllllllllllll}91 & \mathbf{R} & \mathbf{A} & \mathbf{L} & \mathbf{R} & \mathbf{D} & \mathbf{I} & \mathbf{L} & \mathbf{V} & \mathbf{Q} & \mathbf{L} & \mathbf{S} & \mathbf{A} & \mathbf{R} & \mathbf{K} & \mathbf{Y} & \mathbf{L} & \mathbf{H} & \mathbf{S}\end{array}$

271 AGA GCC TTG AGG GAC ATC CTG GTT CAG TTA TCA GCC CGA AAA TAT CTG CAT TCT

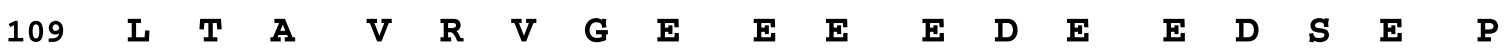

325 CTG ACG GCA GTT CGC GTA GGT GAG GAA GAA GAG GAT GAA GAG GAC TCG GAG CCA

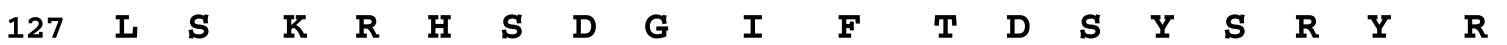

379 CTG TCG AAG CGC CAC TCG GAC GGC ATT TTC ACG GAC AGC TAC AGC CGC TAC CGG

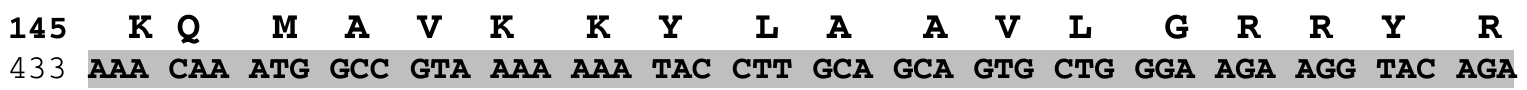

$\begin{array}{llllllllllllll}163 & \mathbf{Q} & \mathbf{R} & \mathbf{F} & \mathbf{R} & \mathbf{N} & \mathbf{K} & \mathbf{G} & \mathbf{R} & \mathbf{R} & \mathbf{F} & \mathbf{A} & \mathbf{Y} & \mathbf{L}\end{array}$

487 CAG AGG TTT AGA AAC AAA GGA CGC CGC TTT GCT TAT TTGTAG CGGATAGGAAGAAAAGG 545

546 AAAGAAAGAAAAAACGCGAGAGAGAGAGAGAGAGAGAGAAATAGAGCAACTGCCCTCCCTTGTGTCCATTC 617

618 AATCATACAGTCAGAAGTCTGGTATCTAACTTAACACTGAGCAGTCAGTCGGTGGATCTCGCCTGTGTTCTT 689 690 TTAAACATGTATTTTATGTACGAAGTCAAGCCATTAAAG

Figure 2 Nucleotide sequence and deduced amino acid sequence of the $C$. gariepinus PRP/PACAP cDNA precursor (GenBank accession number EF524513). The sequence encoding PRP is shaded in gray and the sequence encoding PACAP is in bold and shaded in gray. The signal peptide coding sequence is shown by a single underline. The ATG corresponds to the alternative translation initiation start site, the triplet coding for the stop codon (TGA), and the putative polyadenylation signal (ATTAAA) are in bold and double underlined.

lanes corresponding to lysate supernatants of the E. coli BL21 (DE3) transformed with PRP and PACAP (Fig. 4A). The maximum levels of expression of the target proteins were observed $5 \mathrm{~h}$ after IPTG addition at $28^{\circ} \mathrm{C}$. Expression levels of target proteins fused to intein were identified using rabbit serum raised against the chitin-binding domain that recognizes the intein tag (Fig. 4B). In the lanes corresponding to lysate supernatants of the E. coli BL21 (DE3) transformed with PRP and PACAP, bands of the expected $60 \mathrm{kDa}$ size were identified. This band was absent in the control lysate of E. coli BL21 (DE3) (Fig. 4B). The maltose-binding protein fused in-frame to the coding region of the intein tag was present (data not shown). The non-specific band above $60 \mathrm{kDa}$ was also recognized with rabbit serum against chitin-binding domain in all samples, including negative controls.
Using the inducible self-cleavage activity of the intein in the presence of thiols (cysteine), an efficient release of the target proteins from the intein tag was obtained. The cleavage proteins showed the estimated sizes of the $\sim 5 \mathrm{kDa}$ in the Tris-Tricine gel and were obtained $\sim 50 \%$ pure (Fig. 4C). Both peptides were obtained at about $3 \mathrm{mg}$ per 1 of culture medium. MS analysis of the cleavage proteins (Fig. 4C) demonstrated that these correspond to PRP and PACAP from catfish.

Protein identifications by MS

Signals at $m / z 659 \cdot 62(2+)$ and $514 \cdot 25(2+)$ were observed after tryptic digestion of PRP and lysyl endopeptidase treatment of PACAP respectively. ESI-MS/MS analyses of these peptides are shown in Fig. 5A and B. 


Fish
C.gariepinus
C.macrocephalus
I.punctatus
G.morhua
T.nigroviridis
D.rerio
O.mykiss
C.carpio
C.idella
Tunicate
H.roretzi
Amphibians
X.laevis
R.ridibunda
Birds
O.aries
A.platyrhynchos
G.gallus
Mammalian
C. familiaris
O.cuniculus
S.scrofa
M.musculus
R.norvegicus
H.sapiens
M.fascicularis
P.troglodytes
B.taurus

PRP

HADGLLDRALRDILVQLSARKYLHSLTAVRVGEEE--EDEEDSEPLS 45 HADGIDRAI RDIIVOISARKYI HSITAVRVGEFE- EDEEDSFPIS HADGLLDRALRDILVQLSARKYLHSLTAVRVGEEE--EDEEDSEPLS 45 HAEEELDRALREILGQLTARQYLHSLMTIRVGEET--SMEDESEPLS 45 HAEGELDRALREILGQLTARHYRHFLMTVR-G-----SAE-ESEPLS 40 HADGMFNKAYRKALGQLSARKYLHTLMAKRVGGGST--TEDDNEPLS 45 HADGMFNKAYRKALGQLSARKYLHSLMAKRVSGGST--MEDDSEPLS 45

HADGLLDRALRDILVQLSARKYLHSLMAVRVGGGSS--EEDESEPLS 45

HADELLNKVYRNVLGHLSARKYLHTLMAORLGTVSS-SLEDESEPLS 46 --DFAFDNNPIGIGNPASVFDDMYSFYYPAEKSAVSSSLEDDSEPLS 45 --HGILDKAYRKVLDOLSARRYLOTLMAKGLGGTPGGGADDDSEPLS 45 HADGIFNKAYRKLLGQLSARKYLHSLMAKRVGGASSG-LGDEAEPLT 46 --DFALRAGAPGGGGPRPRWGRCTALYYPPGKSGASSGLGDEAEPLS 45

--QGILNKAYRKVLDQLSARKYLQTLVAKGLGGNLGGGAEDDSEPLS 45 --LGILNKAYRKVLDQLSARKYLQTLMAKGMGENLGGGPEDDLEPLS 45 --HGILNKAYRKVLDQLSARKYLQTLMAKSVGGNLDGGAEDDSEPLS 45 --HEILNEAYRKVLDOLSARKYLOSVVARGAGENLGGSAVDDPAPLT 45 --HEILNEAYRKVLDQLSARKYLQSMVARGMGENLAAAAVDDRAPLT 45 --HGILNEAYRKVLDQLSAGKHLQSLVARGVGGSLGGGAGDDAEPLS 45 --HGILNKAYRKVLDQLSARKYLQSLVAKGVGGSLGGGVEEDAEPLS 45 --HGILNKAYRKVLDQLSARKYLQSLVAKGVGGSLGGGAEDDAEPLS 45 --HGILNKAYRKVLDQPSARRSPADAHGQGLGWDPGGSADDDSEPLS 45

I (\%)
100
100
66
55
60

82


55
20
37
51
11
51
51
53
37
35
35
55
53
24

\section{PACAP}

HSDGIFTDSYSRYRKQMAVKKYLAAVLGRRYRQRFRNK 38 HSDGIFTDSYSRYRKOMAVKKYLAAVLGRRYRORFRNK 38 HSDGIFTDSYSRYRKQMAVKKYLAAVLGRRYRQRFRNK 38 HSDGIFTDSYSRHRKQMAVKKYLAAAVLGRRYRQRVRNK 38 HSDGIFTDSYSRYRKQMAVQKYLAAVLGRRYRQRVRNK 38 HSDGIFTDIYSRYRKOMAVKKYLAAVLGRRYRQRVKNK 38 HSDGIFTDSYSRYRKQMAVKKYLAAVLGKRYRQRYRSK 38 HSDGIFTDIYSRYRKQMAVKKYLAAVLGRRYRQRVKNK 38 HSDGIFTDIYSRYRKQMAVKKYLAAVLGRRYRQRIKNK 38

HSDGIFTDSYSRYRKQMAVKKYLAAVLGKRYRQRYRNE 38

HSDGIFTDSYSRYRKOMAVKKYLAAVLGKRYKORIKNK 38 HSDGIFTDSYSRYRKQMAVKKYLAAVLGKRYKQRIKNK 38

HSDGIFTDSYSRYRKOMAVKKYLAAVLGKRYKQRVKNK 38 HIDGIFTDSF SRYRKQMAVKKYLAAVLGKRYKQRVKNK 38 HIDGIFTDSYSRYRKQMAVKKYLAAVLGKRYKQRVKNK 38

HSDGIFTDSYSRYRKQMAVKKYLAAVLGKRYKQRVKNK 38 HSDGIFTDSYSRYRKQMAVKKYLAAVLGKRYKQRVKNK 38 HSDGIFTDSYSRYRKQMAVKKYLAAVLGKRYKQRVKNK 38 HSDGIFTDSYSRYRKOMAVKKYLAAVLGKRYKORVKNK 38 HSDGIFTDSYSRYRKQMAVKKYLAAVLGKRYKQRVKNK 38 HSDGIFTDSYSRYRKQMAVKKYLAAVLGKRYKQRVKNK 38 HSDGIFTDSYSRYRKOMAVKKYLAAVLGKRYKORVKNK 38 HSDGIFTDSYSRYRKOMAVKKYLAAVLGKRYKORVKNK 38 HSDGIFTDSYSRYRKQMAVKKYLAAVLGKRYKQRVKNK 38 $* * * * * * *: * *: * * * * * *: * * * * * * * *: * *: * *::::$
I (\%)

100 100 94 94 92 92 92 92 92 89 89 89 84 86 89 89 89 89 89 89
89 89 89

Figure 3 Comparison of PRP and PACAP sequences among species. Sequence analysis comparison was made by CLUSTALW analysis (http://www.ebi.ac.uk/Tools/clustalw) among PRP/PACAP amino acid sequences reported for Clarias macrocephalus (CAA55684), Ictalurus punctatus (AAK66970), Gadus morhua (AAZ85701), Tetraodon nigroviridis (CAG12289), Danio rerio (AAH83516), Oncorhynchus mykiss (AAK28557), Cyprinus carpio (BAD01118), Ctenopharyngodon idella (EF592488), Halocynthia roretzi (BAD01117), Xenopus laevis (AAD56956), Rana ridibunda (AAF74571), Ovis aries (NP_001009776), Anas platyrhynchos (ABE01122), Gallus gallus (AAX56089), Canis familiaris (XP_849191), Oryctolagus cuniculus (ABD78945), Sus scrofa (AAD12780), Mus musculus (BAC37673), Rattus norvegicus (NP_058685), Homo sapiens (NP_001108), Macaca fascicularis (AAW59436), Pan troglodytes (XP_001147286), Bos taurus

(NP_001040020), and that obtaine-d from C. gariepinus (EF524513). The GenBank accession numbers of the sequences are indicated in the parentheses. *Indicates the conserved amino acids. :, Indicates similar amino acid. ., Indicates different amino acid. I, identity percentage among species; $S$, peptide size in amino acid.

Both spectra were manually analyzed and very reliable extracted sequences were used to confirm the identity of the characterized proteins. In the sequence databases, the extracted peptide sequences corresponded to the N-terminal end of PACAP and PRP polypeptides.

Table 3 shows all signals obtained and their respective sequences assigned by ESI-MS/MS analysis. Differences between $m / z$ observed and calculated were associated with the internal error of the mass spectrometer (below $50 \mathrm{ppm}$ ). The chemical modification observed in aspartic acid was generated by E. coli post-translation modifications.

Growth-promoting activity of the recombinant C. gariepinus $P R P$ and $P A C A P$ in fish larvae

Experiments were performed to evaluate the biological effect of the recombinant $C$. gariepinus PRP and PACAP on the growth rate of catfish (C. gariepinus), tilapia (O. niloticus), and carp (C. carpio). The effect of these peptides on fish growth was determined by measuring the increase in body weight and length.

\section{Growth-promoting activity in C. gariepinus larvae}

The PRP- and PACAP-treated groups showed a significant increase in body weight and length compared with the control and BL21 groups, 8 days after treatment $(P<0 \cdot 01)$. After 15 days, both weight and length increments, when compared with the BL21 and control groups, were highly significant $(P<0 \cdot 001)$. Statistically significant differences

Table 2 Effects of the recombinant $C$. gariepinus pituitary adenylate cyclase-activating polypeptide (PACAP) and PACAP-related peptide (PRP) expressed in baby hamster kidney (BHK)-21 cells on growth hormone $(\mathrm{GH})$ secretion by cultured tilapia pituitary cells. Data represent arithmetic mean of the tilapia $\mathrm{GH} \pm$ s.D.

\section{GH concentration $(\mathrm{ng} / \mathrm{ml})$}

\begin{tabular}{|c|c|}
\hline $24 \mathrm{~h}$ & $48 \mathrm{~h}$ \\
\hline $15 \cdot 01+0.93^{b}$ & $22 \cdot 79+5 \cdot 21^{b}$ \\
\hline $14 \cdot 97 \pm 1 \cdot 89^{b}$ & $22 \cdot 23 \pm 5 \cdot 78^{b}$ \\
\hline $8.02 \pm 0.81$ & $12 \cdot 60 \pm 2 \cdot 36$ \\
\hline $9 \cdot 21 \pm 1 \cdot 79$ & $10 \cdot 67 \pm 2 \cdot 84$ \\
\hline${ }_{-}^{d}-1-1$ & $12 \cdot 37 \pm 1 \cdot 25$ \\
\hline$-^{d}$ & $22 \cdot 19 \pm 3 \cdot 76^{\mathrm{C}}$ \\
\hline$-^{d}$ & $14 \cdot 67 \pm 2 \cdot 63$ \\
\hline
\end{tabular}

${ }^{\mathrm{a}}$ Treatments were tested in duplicate, with three to four fish pituitaries each test.

${ }^{\mathrm{b}}$ Statistical differences with respect to the negative and pTargeT controls $(P<0 \cdot 05)$.

${ }^{\mathrm{c}}$ Statistical differences with respect to negative control $(P<0 \cdot 05)$.

${ }^{\mathrm{d}}$ Not measured. 
A

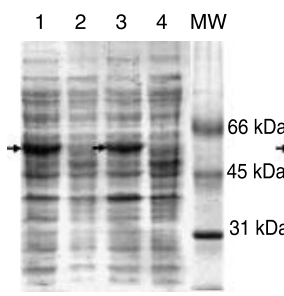

Figure 4 Recombinant expression in E. coli, immune identification, and semi-purification of the C. gariepinus PRP and PACAP. (A and B) Glycine-SDS-PAGE and western blotting respectively to analyze the expression of the PRP and PACAP in E. coli. Protein expressions were performed at $28{ }^{\circ} \mathrm{C}$ for $5 \mathrm{~h}$. Lanes 1 and 2: lysis supernatant and pellet respectively from E. coli BL21 (DE3) transformed with pTYB1-PRP expression vector. Lanes 3 and 4: lysis supernatant and pellet respectively from $E$. coli BL21 (DE3) transformed with pTYB1PACAP. MW, broad-range protein marker (Bio-Rad). Lanes 5 and 6: lysis supernatant and pellet from $E$. coli BL21 (DE3) transformed with pTYB1. (C) Tricine-SDS-PAGE analysis from PRP and PACAP semi-purification. The target proteins were obtained $\sim 50 \%$ pure. Lanes 1 and 2: lysis supernatants from E. coli BL21 (DE3) transformed with pTYB1-PRP and pTYB1-PACAP respectively treated with $0.5 \mathrm{mM}$ of cysteine solution $\mathrm{pH} 9$ overnight at $4{ }^{\circ} \mathrm{C}$, clarified by centrifugation at $10000 \mathrm{~g}$ for $30 \mathrm{~min}$, and dialyzed overnight at $4{ }^{\circ} \mathrm{C}$ against PBS $1 \times$. The identity of the shown semipurified peptides was demonstrated by mass spectrometry (Fig. 5). Arrows denote the target proteins.

$(P<0.05)$ in body weight increment in the PACAP-treated group, when compared with PRP treated groups, were also observed at 21 days (Fig. 6A and B). No statistical difference in increase in length was observed between the PRP and PACAP groups at that time (Fig. 6B).

No statistical difference in body weight increase and length was observed in the BL21 group when compared with the control group in the experiment (Fig. 6A and B).
Growth-promoting activity in $\mathrm{O}$. niloticus larvae

Eight days after the start of the experiment, the PRP- and PACAP-treated groups showed a significant increase in body weight and length compared with the control group $(P<0 \cdot 05)$. The difference in body weight increment between the PACAP-treated group and the BL21 group was highly significant $(P<0 \cdot 001)$ at days 15 and 21 , and a statistically significant difference was also observed between PACAP- and PRP-treated groups $(P<0.05)$ during these times (Fig. 7A and $\mathrm{B})$. No statistical difference in increase in length was observed between the PRP and PACAP groups during the experiment (Fig. 7B).

\section{Growth-promoting activity in C. carpio larvae}

The PACAP-treated group showed a statistically significant increase in body weight and length compared with the BL21 group, 8 days after the start of the experiment $(P<0 \cdot 01$; Fig. 8). Statistically significant increase in the body weight $(P<0 \cdot 05)$ and length $(P<0 \cdot 01)$ between the PRP- and BL21-treated groups were also observed at this time. At day 15 , the differences in the body weight of the PACAP-treated groups, when compared with the BL21 group were highly significant $(P<0 \cdot 001)$. At day 27 , statistically significant differences in body weight increase were observed between the PACAP- and PRP-treated group $(P<0 \cdot 05)$. Statistically significant differences were also observed in the increase in length in the PRP- and PACAP-treated groups when compared with the BL21 group 8 days $(P<0.01)$ and 15 days $(P<0 \cdot 001)$ after the start of the experiment, but no statistically significant difference was detected in the length average between the PRP and PACAP groups during the experiment (Fig. 8).
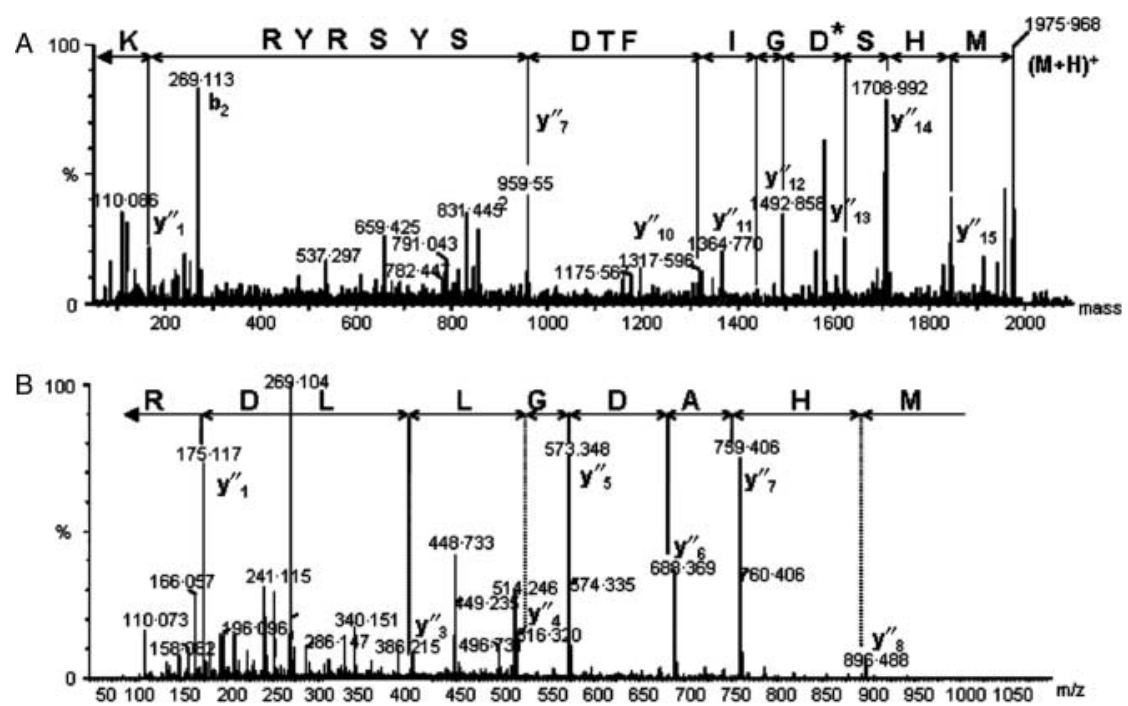

Figure 5 ESI-MS/MS spectra of the N-terminal peptides for (A) PACAP $m / z 659 \cdot 62(3+)$ and (B) PRP $m / z 514 \cdot 25(2+)$ polypeptides. 
Table 3 Peptide sequences identified by mass spectrometry of the recombinant pituitary adenylate cyclase-activating polypeptide (PACAP)related peptide (PRP) and PACAP expressed in E. coli

\begin{tabular}{|c|c|c|c|c|}
\hline & \multirow[b]{2}{*}{ Peptide sequence } & \multicolumn{2}{|c|}{ Mass/charge ratio ${ }^{a}$} & \multirow[b]{2}{*}{ Charge } \\
\hline & & Observed & Calculated & \\
\hline \multicolumn{5}{|l|}{ Peptides } \\
\hline \multirow[t]{2}{*}{ PACAP } & ${ }^{1} \mathrm{MHSD}^{\mathrm{b}}$ GIFTDSYSRYRK ${ }^{16}$ & $659 \cdot 62$ & $659 \cdot 64$ & 3 \\
\hline & ${ }^{22}$ YLAAVLGR ${ }^{29}$ & $431 \cdot 76$ & $431 \cdot 75$ & 2 \\
\hline \multirow[t]{3}{*}{ PRP } & ${ }^{1} \mathrm{MHADGLLDR}^{9}$ & $514 \cdot 25$ & $514 \cdot 25$ & 2 \\
\hline & ${ }^{13}$ DILVQLSAR $^{21}$ & $507 \cdot 80$ & $507 \cdot 80$ & 2 \\
\hline & ${ }^{32}$ VGEEEEDEEDSEPLS ${ }^{46}$ & $846 \cdot 84$ & $846 \cdot 84$ & 2 \\
\hline
\end{tabular}

${ }^{\mathrm{a}}$ Mass accuracy determination was below $50 \mathrm{ppm}$.

${ }^{b} \mathrm{D}$ aspartic acid expected, mass difference corresponds to methyl aspartic acid.

The carp larvae treated with PACAP showed precocity in their skin pigmentation when compared with the BL21-treated group. At 27 days, the PACAP-treated group had red pigmentation on $24 \%$ of their total body surfaces, whereas the PRP- and BL21-treated fish showed only 5\% and $9 \%$ respectively (Table 4).

\section{Discussion}

We have isolated from African catfish (C. gariepinus) the cDNA encoding a single precursor containing both PRP and PACAP. The organization of the precursor is similar to that described in other non-mammals: signal peptide, cryptic peptide, PRP, PACAP, and 3'-UTR (Adams et al. 2002). The deduced amino acid sequence of the C. gariepinus PACAP is
$89 \%$ identical to the $H$. sapiens sequence, whereas the PRP is only 35\% identical to human PRP. The high conservation of the PACAP peptide sequence throughout evolution points to an important role for this molecule (Vaudry et al. 2000). This finding is in agreement with the multiple biological functions described for this peptide, which include hypophysiotropic, neurotransmitter, neuromodulator, and vasoregulatory activities (Carlsson et al. 1996, Wong et al. 1998, Shioda et al. 2006). The low conservation of the PRP sequence suggests that its function is less critical and could even be lost during evolution. This hypothesis may be supported by phylogenetic studies that appear to indicate the loss of the PRP receptor in the mammalian genome (Lee et al. 2007).

In the present work, using hemipituitary gland culture from tilapia (O. niloticus), we established that C. gariepinus PRP and PACAP are able to stimulate GH secretion in vitro.
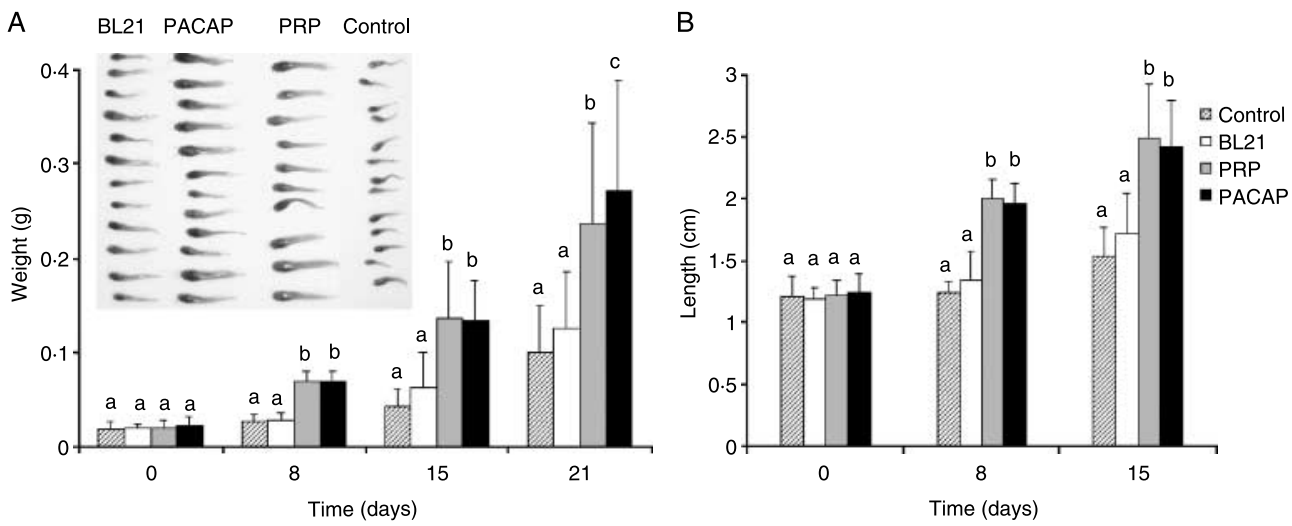

Figure 6 Growth promotion experiment in C. gariepinus larvae $(n=200)$ immersed in the $E$. coli-derived PACAP and PRP at a dose of $200 \mu \mathrm{g} / \mathrm{l}$ of water. (A) Effect on body weight over 21-day period. The picture was taken at 21 days of treatment. (B) Effect on length over 15-day period. Samples of 25 animals were weighted and sized at 0,8 , and 15 days. Samples of 80 animals were weighted at 21 days. Control group: did not receive any treatment. BL21 group: received lysis supernatant from E. coli BL21 (D3) transformed with pTYB1 vector. PRP group: received lysis supernatant from E. coli BL21 (DE3) transformed with pTYB1-PRP vector. PACAP group: received lysis supernatant from E. coli BL21 (DE3) transformed with pTYB1-PACAP vector. Newman-Keuls multiple comparison test was used for body weight comparison among groups at days 0 and 8 ; the letter ' $b$ ' indicates $P<0 \cdot 01$. Kruskal-Wallis test followed by Dunn's multiple comparison post-test was used at days 15 and 21; the letter ' $b$ ' indicates $P<0 \cdot 001$ and ' $c$ ' $P<0 \cdot 001$ with respect to control and BL21 groups and $P<0 \cdot 05$ with respect to PRP group. In the case of length, Newman-Keuls multiple comparison test was used at days 0,8 , and 15; the letter ' $\mathrm{b}$ ' indicates $P<0.01$ at 8 days and $P<0.001$ at 15 days and ' $\mathrm{a}$ ' $P>0.05$. Bars indicate s.D. 

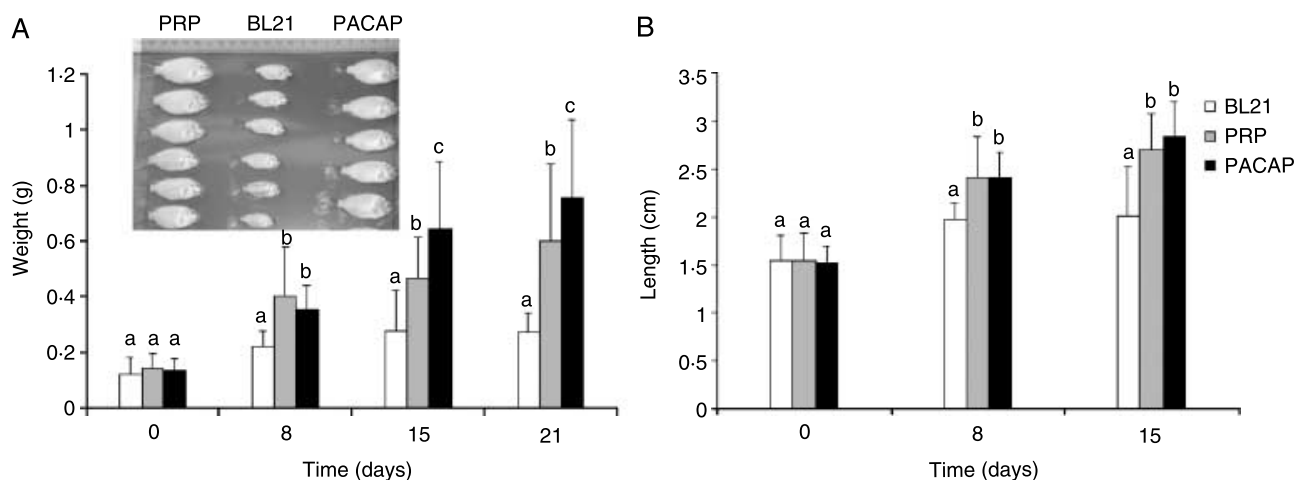

Figure 7 Growth promotion experiment in O. niloticus larvae $(n=150)$ immersed in the $E$. coli-derived PACAP and PRP at a dose of $200 \mu \mathrm{g} / \mathrm{l}$ of water. (A) Effect on body weight over 21-day period. The picture was taken at 30 days after the last immersion bath (carried out at 21 days after the start of the experiment). (B) Effect on length over 15-day period. Samples of 25 animals were weighted and sized at 0, 8, and 15 days. Samples of 50 animals were weighted at 21 days. BL21 group: received lysis supernatant from E. coli BL21 (D3) transformed with pTYB1 vector. PRP group: received lysis supernatant from E. coli BL21 (DE3) transformed with pTYB1-PRP vector. PACAP group: received lysis supernatant from E. coli BL21 (DE3) transformed with pTYB1-PACAP vector. Newman-Keuls multiple comparison test was used for body weight comparison among groups at days 0 and 15 ; the letter ' $b$ ' indicates $P<0.05$, and ' $c$ ' $P<0.001$ with respect to BL21 group and $P<0.05$ with respect to PRP group. Kruskal-Wallis test followed by Dunn's multiple comparison post-test was used at days 8 and 21 . In these cases, the letter ' $\mathrm{b}^{\prime}$ ' indicates $P<0.05$ at day 8 and $P<0.01$ at day 21 and ' $\mathrm{c}^{\prime} P<0.001$ at day 21 with respect to BL21 group and $P<0 \cdot 05$ with respect to PRP group. In the case of length, Newman-Keuls multiple comparison test was used at days 0 and 15; the letter ' $b$ ' indicates $P<0 \cdot 01$ between PRP and BL21 groups and $P<0 \cdot 001$ between PACAP and BL21 groups. Kruskal-Wallis test followed by Dunn's multiple comparison post-test was used at day 8 ; the letter ' $b$ ' indicates $P<0 \cdot 05$ and ' $a$ ' $P>0 \cdot 05$. Bars indicate s.D.

Dose-dependent increases in $\mathrm{GH}$ secretion were observed when the pituitary glands were treated with GHRP-6 as positive control. Partial desensitization can occur at high concentrations of GHRP-6 (12 nM) probably by negative feedback signals (Giustina \& Veldhuis 1998).

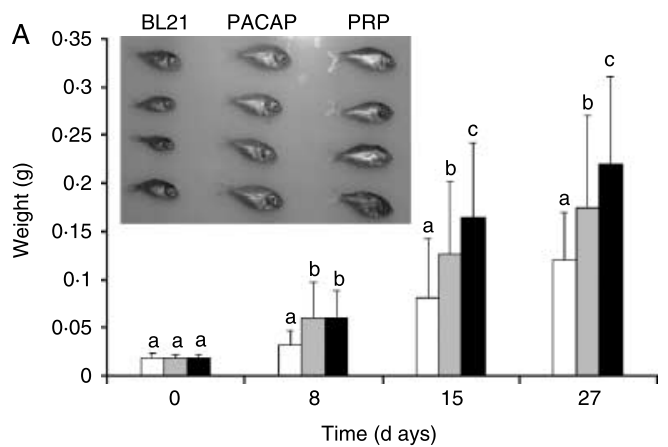

The PACAP effects in GH release have been demonstrated in vitro in some species of mammals (Hart et al. 1992, Jarry et al. 1992, Hashizume et al. 1994, Sawangjaroen \& Curlewis 1994, Chiodera et al. 1996, Sawangjaroen et al. 1997, Martinez-Fuentes et al. 1998), birds (Peeters et al. 1998),

Figure 8 Growth promotion experiment in C. carpio larvae $(n=450)$ immersed in the $E$. coli-derived PACAP and PRP at a dose of $200 \mu \mathrm{g} / \mathrm{l}$ of water. (A) Effect on body weight over 27-day period. The picture was taken at 27 days of treatment. (B) Effect on length over 15-day period. Samples of 25 animals were weighted and sized at 0,8 , and 15 days. Sample of 150 animals were weighted at 27 days. BL21 group: received lysis supernatant from E. coli BL21 (D3) transformed with PTYB1 vector. PRP group: received lysis supernatant from $E$. coli BL21 (DE3) transformed with pTYB1-PRP vector. PACAP group: received lysis supernatant from E. coli BL21 (DE3) transformed with pTYB1-PACAP vector. Newman-Keuls multiple comparison test was used for body weight comparison among groups at days 0 and 15 ; the letter ' $b$ ' indicates $P<0.05$ between PRP and BL21 groups and $P<0.001$ between PACAP and BL21 groups. Kruskal-Wallis test followed by Dunn's multiple comparison post-test was used at days 8 and 27 ; the letter ' $b$ ' indicates $P<0.05$ between PRP and BL21 groups, $P<0 \cdot 01$ between PACAP and BL21 groups at day 8 , and $P<0 \cdot 01$ between PRP and BL21 groups at day 27, and the letter ' $C$ ' indicates $P<0 \cdot 001$ between PACAP and BL21 groups and $P<0 \cdot 05$ between PRP and PACAP groups. In the case of length, Newman-Keuls multiple comparison test was used at days 0,8 , and 15; the letter ' $b$ ' indicates $P<0 \cdot 01$ at day 8 and $P<0 \cdot 001$ at day 27 and 'a' $P>0 \cdot 05$. Bars indicate s.D. 
Table 4 Skin color development in carp larvae (Cyprinus sp.) treated by immersion with recombinant pituitary adenylate cyclaseactivating polypeptide (PACAP) or PACAP-related peptide peptides expressed in E. coli at a dose of $200 \mu \mathrm{g} / \mathrm{l}$ of water. Skin pigmentation was determined by visual evaluation and photography at day 27 from treatment. Data are given as the percentage of the total fish showing red, green, or both (red/green) skin pigments

Skin pigmentation $(\%)^{\mathrm{a}}$

Red Red/green Green

$\begin{array}{lrrr}\text { Treatment } & & & \\ \text { BL21 } & 4 \cdot 2 & 31 \cdot 7 & 64 \cdot 1 \\ \text { PRP } & 8 \cdot 8 & 36 \cdot 8 & 54 \cdot 4 \\ \text { PACAP } & 24 \cdot 2 & 48 \cdot 4 & 27 \cdot 3\end{array}$

${ }^{\text {aH }}$ undred and fifty animals were characterized in each treated group.

amphibians (Gracia-Navarro et al. 1992, Yon et al. 1993), and fish (Parker et al. 1997, Montero et al. 1998, Wong et al. 1998, Xiao et al. 2002, Wong et al. 2005). Studies to investigate the effect of PACAP on GH secretion in mammals showed contradictory results. Some data suggest that PACAP stimulates GH release in rat (Hart et al. 1992, Jarry et al. 1992) and sheep (Sawangjaroen et al. 1997). However, in humans, i.v. administration of PACAP does not modify plasma GH levels (Chiodera et al. 1996). Also, PACAP is less potent than GHRH in stimulating $\mathrm{GH}$ release from somatotropic adenoma cells in primary culture (Adams et al. 1994). These findings suggest that, in mammals, the PACAP effect on GH secretion may vary from species to species. In fish, PRP exerts a modest GH stimulatory effect in vitro in trout (Oncorhynchus mykiss) (Luo et al. 1990), carp (C. carpio) (Vaughan et al. 1992), tilapia hybrid O. niloticus $\times$ Oreochromis aureus (Melamed et al. 1995), and salmon (Oncorhynchus nerka) (Parker et al. 1997). By contrast, PACAP provokes a robust stimulation of GH release from goldfish (Carassius auratus) (Wong et al. 1998), eel (Montero et al. 1998), and grass carp (Ctenopharyngodon idellus) (Sze et al. 2007) pituitary cells.

In this study, C. gariepinus PRP and PACAP were able to stimulate GH secretion by the tilapia pituitary gland in vitro. This observation suggests that both peptides are involved in the neuroendocrine control of the somatotroph cell activity in teleost fish. This positive response was observed for in vitro static hemipituitary gland culture even though these always lack some of the regulatory factors present in vivo.

There are few studies about the effect of PACAP on GH secretion in vivo. It is known that this peptide increases the GH levels in rat and bovine plasma in vivo (Jarry et al. 1992, Radcliff et al. 2001), whereas in ewes and humans it does not produce this effect (Sawangjaroen \& Curlewis 1994, Chiodera et al. 1996). To date, there have been no previous in vivo studies that show the PACAP and PRP functions with regard to $\mathrm{GH}$ stimulation and growth regulation in fish. In this work, the biological effect of the C. gariepinus recombinant PRP and PACAP, administered by immersion baths, on the growth rate of C. gariepinus, O. niloticus, and C. carpio larvae was evaluated.
We have reported for the first time an efficient recombinant expression of fish PRP and PACAP in E. coli and demonstrated that the growth rate of fish is enhanced by both PRP and PACAP administrations.

The immersion bath method successfully used for our studies requires little manipulation and causes minimum stress to fish during treatment (Nakanishi \& Ototake 1997). There is evidence suggesting that the gill pillar cells are a possible entry site for some molecules when fish are treated by immersion bath (Sherwood \& Harvey 1986, Moriyama \& Kawauchi 1990, Nakanishi \& Ototake 1997). For example, in goldfish, gonadotropin-releasing hormone appeared quickly in the plasma following its application to gills (Sherwood \& Harvey 1986). In our laboratory, we have employed the immersion bath technique to study the effects of nutritional supplements and growth factors on growth control and the immune system in fish (Martinez et al. 2006, Acosta et al. 2007, Carpio et al. 2007).

In this study, as early as 1 week after the application of the E. coli-derived PRP and PACAP, statistically significant increase in body weight and length were obtained in the treated fish larvae when compared with control groups. This result is potentially important to the fish farming industry considering that the highest levels of fish losses occur during the early developmental stages.

We have also observed in the carp larvae treated with recombinant C. gariepinus PACAP a precocity in the skin pigmentation change. This observation is consistent with recent studies in Xenopus laevis that demonstrated a physiological function of the PACAP/VIP family of peptides in the regulation of the melanotroph cell activity during the process of skin color adaptation (Kidane et al. 2007). Additional studies would be required to elucidate the molecular action of PACAP in skin color development in fish.

The results presented here also confirmed that the PRP and PACAP biological functions are well conserved in fish, since C. gariepinus PRP and PACAP stimulate growth in O. niloticus and C. carpio larvae as well as in C. gariepinus larvae. In accord with previous in vitro studies suggesting that fish PACAP has greater ability than PRP to stimulate secretion of GH in fish (Parker et al. 1997), we have demonstrated for the first time that PACAP rather than PRP plays a physiological role in the growth control in teleost fish.

The minor effect of the recombinant C. gariepinus PRP on growth performance in tilapia and carp larvae could be attributed to species specificity, inasmuch as the structure of PRP has been less conserved than other hypophysiotropic neuropeptides. In addition, using sequence alignment and phylogenetic analysis, Tam et al. (2007) demonstrated that in zebrafish, fugu, tetraodon, stickleback, and goldfish, two distinct PRPs (salmon like and catfish like) could be discerned. The two peptides could also differ in their biological activity. The higher growth-promoting effect observed in C. gariepinus larvae treated with recombinant $C$. gariepinus PACAP, when compared with PRP, suggests an earlier role for PACAP, than PRP, in the growth control in teleost fish. 
Growth in fish is regulated by the brain neuroendocrineGH-insulin-like growth factor axis (Peter \& Marchant 1995). GH plays an important role as metabolic regulator, especially in stimulating lipid mobilization and protein increase, both of which encourage growth in fish (Hernandez Llorente et al. 2004). In the present study, we observed an increase in GH secretion in fish pituitary glands treated with both PACAP and PRP, when compared with control groups. Taking into account our results and the well-known effects of GH in vertebrate growth, the action of PRP and PACAP in fish growth enhancement might be mediated by GH. However, it remains to be elucidated whether the action of these neuropeptides on fish growth is achieved solely through GH stimulation or in conjunction with another, more direct mechanism affecting cell growth. In previous investigations, it was demonstrated that PACAP exerts direct trophic effects on rat cerebellar cortex during development (Vaudry et al. 1999). Certainly, further studies are necessary to investigate the possible trophic action of PACAP in teleost fish in cells other than somatotrophs.

As a matter of fact, PACAP has been implicated in a broad range of biological processes in higher vertebrates, including reproduction, development, growth, cardiovascular, respiratory, and digestive functions, immune responses, and circadian rhythms (Vaudry et al. 2000). However, there are few in vivo studies showing its biological activities in fish (Matsuda et al. 2005a,b, Sherwood \& Wu 2005, Matsuda \& Maruyama 2007). Until now, there have been no in vivo studies showing PRP and PACAP activity in fish growth enhancement. Recently, we have also demonstrated PACAP action as a regulator of the teleostean immune system, together with its physiological role in growth control in fish (Carpio \& Lugo unpublished observations). Our studies thus far identify PACAP as a prominent target with the potential to stimulate fish growth in aquaculture. In this direction, further research is needed to fully evaluate its potential as a novel fish biotechnology product.

In summary, the results obtained here by in vitro and in vivo administration of recombinant PRP and PACAP to fish showed for the first time the biological role of these neuropeptides in fish growth and development. This finding contributes toward our understanding of the neuroendocrine axis proposed to explain the hypothalamic regulation of growth in non-mammalian vertebrates. This finding also might lead to a powerful new biotechnology tool to further develop modern fish farming.

\section{Acknowledgements}

The authors would like to appreciate Dr John van der Meer (President of PAMBA) for his precious help in the manuscript revision. We wish to thank Sheila Cabezas and Lidice Bernardo for their invaluable help to improve on earlier drafts of this manuscript. The authors declare that there is no conflict of interest that would prejudice the impartiality of this scientific work.

\section{References}

Acosta J, Morales R, Morales A, Alonso M \& Estrada MP 2007 Pichia pastoris expressing recombinant tilapia growth hormone accelerates the growth of tilapia. Biotechnology Letters 29 1671-1676.

Adams EF, Buchfelder M, Petersen B \& Fahlbusch R 1994 Effect of pituitary adenylate cyclase-activating polypeptide on human somatotrophic tumours in cell culture. Endocrine Journal 2 75-79.

Adams BA, Lescheid DW, Vickers ED, Crim LW \& Sherwood NM 2002 Pituitary adenylate cyclase-activating polypeptide and growth hormonereleasing hormone-like peptide in sturgeon, whitefish, grayling, flounder and halibut: cDNA sequence, exon skipping and evolution. Regulatory Peptides 109 27-37.

Alexandre D, Vaudry H, Jegou S \& Anouar Y 2000 Structure and distribution of the mRNAs encoding pituitary adenylate cyclase-activating polypeptide and growth hormone-releasing hormone-like peptide in the frog, Rana ridibunda. Journal of Comparative Neurology 421 234-246.

Bertherat J, Bluet-Pajot MT \& Epelbaum J 1995 Neuroendocrine regulation of growth hormone. European Journal of Endocrinology 132 12-24.

Campbell RM \& Scanes CG 1992 Evolution of the growth hormonereleasing factor (GRF) family of peptides. Growth Regulation 2 175-191.

Carlsson PO, Ostenson CG, Efendic S, Langel U \& Jansson L 1996 Pituitary adenylate cyclase activating polypeptide (PACAP) redistributes the blood within the pancreas of anesthetized rats. Regulatory Peptides 63 123-128.

Carpio Y, Leon K, Acosta J, Morales R \& Estrada MP 2007 Recombinant tilapia Neuropeptide $\mathrm{Y}$ promotes growth and antioxidant defenses in African catfish (Clarias gariepinus) fry. Aquaculture $\mathbf{2 7 2}$ 649-655.

Chan KW, Yu KL, Rivier J \& Chow BK 1998 Identification and characterization of a receptor from goldfish specific for a teleost growth hormone-releasing hormone-like peptide. Neuroendocrinology 68 44-56.

Chiodera P, Volpi R, Capretti L, Caffarri G, Magotti MG \& Coiro V 1996 Effects of intravenously infused pituitary adenylate cyclase-activating polypeptide on adenohypophyseal Hormone secretion in normal men. Neuroendocrinology 64 242-246.

Giustina A \& Veldhuis JD 1998 Pathophysiology of the neuroregulation of growth hormone secretion in experimental animals and the human. Endocrine Reviews 19 717-797.

Gonzalez BJ, Basille M, Vaudry D, Fournier A \& Vaudry H 1998 Pituitary adenylate cyclase-activating polypeptide. Annales d'Endocrinologie $\mathbf{5 9}$ 364-405.

Gonzalez LJ, Castellanos-Serra L, Badock V, Diaz M, Moro A, Perea S, Santos A, Paz-Lago D, Otto A, Muller EC et al. 2003 Identification of nuclear proteins of small cell lung cancer cell line H82: an improved procedure for the analysis of silver-stained proteins. Electrophoresis $\mathbf{2 4}$ $237-252$.

Gracia-Navarro F, Lamacz M, Tonon MC \& Vaudry H 1992 Pituitary adenylate cyclase-activating polypeptide stimulates calcium mobilization in amphibian pituitary cells. Endocrinology 131 1069-1074.

Guillemin R, Brazeau P, Bohlen P, Esch F, Ling N \& Wehrenberg WB 1982 Growth hormone-releasing factor from a human pancreatic tumor that caused acromegaly. Science 218 585-587.

Hart GR, Gowing H \& Burrin JM 1992 Effects of a novel hypothalamic peptide, pituitary adenylate cyclase-activating polypeptide, on pituitary hormone release in rats. Journal of Endocrinology 134 33-41.

Hashizume T, Soliman EB \& Kanematsu S 1994 Effects of pituitary adenylate cyclase-activating polypeptide (PACAP), prostaglandin E2 (PGE2) and growth hormone releasing factor (GRF) on the release of growth hormone from cultured bovine anterior pituitary cells in vitro. Domestic Animal Endocrinology 11 331-337.

Hernandez Llorente MD, Dato Gomez MJ, de Costa Ruiz J, Mendiola Lopez P \& Zamora Navarro S 2004 Effect of recombinant human GH and GHRH on plasma metabolite levels in rainbow trout (Oncorhynchus mykiss). Journal of Physiology and Biochemistry 60 211-218. 
Hosoya M, Kimura C, Ogi K, Ohkubo S, Miyamoto Y, Kugoh H, Shimizu M, Onda H, Oshimura M, Arimura A et al. 1992 Structure of the human pituitary adenylate cyclase activating polypeptide (PACAP) gene. Biochimica et Biophysica Acta 1129 199-206.

Jarry H, Leonhardt S, Schmidt WE, Creutzfeldt W \& Wuttke W 1992 Contrasting effects of pituitary adenylate cyclase activating polypeptide (PACAP) on in vivo and in vitro prolactin and growth hormone release in male rats. Life Science $\mathbf{5 1} 823-830$.

Kidane AH, Cruijsen PM, Ortiz-Bazan MA, Vaudry H, Leprince J, KuijpersKwant FJ, Roubos EW \& Jenks BG 2007 Actions of PACAP and VIP on melanotrope cells of Xenopus laevis. Peptides 28 1790-1796.

Lee LT, Siu FK, Tam JK, Lau IT, Wong AO, Lin MC, Vaudry H \& Chow BK 2007 Discovery of growth hormone-releasing hormones and receptors in nonmammalian vertebrates. PNAS 104 2133-2138.

Luo DS, McKeown BA, Rivier J \& Vale W 1990 In vitro responses of rainbow trout (Oncorhynchus mykiss) somatotrophs to carp growth hormonereleasing factor (GRF) and somatostatin. General and Comparative Endocrinology 80 288-298.

Martinez R, Carpio Y, Gomez Y, Raices M, Morales A, Herrera F, Gonzalez O, Morales R \& Estrada MP 2006 Acuabio 1 stimulates anaerobic metabolism and the immune system in goldfish and tilapia larvae. Biotecnología Aplicada 23 294-299.

Martinez-Fuentes AJ, Malagon MM, Castano JP, Garrido-Gracia JC \& Gracia-Navarro F 1998 Pituitary adenylate cyclase-activating polypeptide (PACAP) 38 and PACAP27 differentially stimulate growth hormone release and mRNA accumulation in porcine somatotropes. Life Science $\mathbf{6 2}$ $2379-2390$

Matsuda K \& Maruyama K 2007 Regulation of feeding behavior by pituitary adenylate cyclase-activating polypeptide (PACAP) and vasoactive intestinal polypeptide (VIP) in vertebrates. Peptides 28 1761-1766.

Matsuda K, Maruyama K, Miura T, Uchiyama M \& Shioda S 2005a Anorexigenic action of pituitary adenylate cyclase-activating polypeptide (PACAP) in the goldfish: feeding-induced changes in the expression of mRNAs for PACAP and its receptors in the brain, and locomotor response to central injection. Neuroscience Letters 386 9-13.

Matsuda K, Nagano Y, Uchiyama M, Onoue S, Takahashi A, Kawauchi H \& Shioda S 2005b Pituitary adenylate cyclase-activating polypeptide (PACAP)-like immunoreactivity in the brain of a teleost, Uranoscopus japonicus: immunohistochemical relationship between PACAP and adenohypophysial hormones. Regulatory Peptides 126 129-136.

McRory J \& Sherwood NM 1997 Two protochordate genes encode pituitary adenylate cyclase-activating polypeptide and related family members. Endocrinology 138 2380-2390.

McRory JE, Parker DB, Ngamvongchon S \& Sherwood NM 1995 Sequence and expression of cDNA for pituitary adenylate cyclase activating polypeptide (PACAP) and growth hormone-releasing hormone (GHRH)like peptide in catfish. Molecular and Cellular Endocrinology 108 169-177.

McRory JE, Parker RL \& Sherwood NM 1997 Expression and alternative processing of a chicken gene encoding both growth hormone-releasing hormone and pituitary adenylate cyclase-activating polypeptide. DNA and Cell Biology 16 95-102.

Melamed P, Eliahu N, Levavi-Sivan B, Ofir M, Farchi-Pisanty O, Rentier-Delrue F, Smal J, Yaron Z \& Naor Z 1995 Hypothalamic and thyroidal regulation of growth hormone in tilapia. General and Comparative Endocrinology 97 13-30.

Miyata A, Arimura A, Dahl RR, Minamino N, Uehara A, Jiang L, Culler MD \& Coy DH 1989 Isolation of a novel 38 residue-hypothalamic polypeptide which stimulates adenylate cyclase in pituitary cells. Biochemical and Biophysical Research Communications 164 567-574.

Miyata A, Jiang L, Dahl RD, Kitada C, Kubo K, Fujino M, Minamino N \& Arimura A 1990 Isolation of a neuropeptide corresponding to the N-terminal 27 residues of the pituitary adenylate cyclase activating polypeptide with 38 residues (PACAP38). Biochemical and Biophysical Research Communications 170 643-648.

Montero M, Yon L, Rousseau K, Arimura A, Fournier A, Dufour S \& Vaudry H 1998 Distribution, characterization, and growth hormone-releasing activity of pituitary adenylate cyclase-activating polypeptide in the European eel, Anguilla anguilla. Endocrinology 139 4300-4310.
Montero M, Yon L, Kikuyama S, Dufour S \& Vaudry H 2000 Molecular evolution of the growth hormone-releasing hormone/pituitary adenylate cyclase-activating polypeptide gene family. Functional implication in the regulation of growth hormone secretion. Journal of Molecular Endocrinology 25 157-168.

Moriyama S \& Kawauchi H 1990 Growth stimulation of juvenile salmonids by immersion in recombinant salmon growth hormone. Nippon Suisan Gakkai Shi 56 31-34.

Nakanishi T \& Ototake M 1997 Antigen uptake and immune responses after immersion vaccination. Developments in Biological Standardization 90 59-68.

Parker DB, Coe IR, Dixon GH \& Sherwood NM 1993 Two salmon neuropeptides encoded by one brain cDNA are structurally related to members of the glucagon superfamily. European Journal of Biochemistry 215 439-448.

Parker DB, Power ME, Swanson P, Rivier J \& Sherwood NM 1997 Exon skipping in the gene encoding pituitary adenylate cyclase-activating polypeptide in salmon alters the expression of two hormones that stimulate growth hormone release. Endocrinology 138 414-423.

Peeters K, Langouche L, Vandesande F, Darras VM \& Berghman LR 1998 Effects of pituitary adenylate cyclase-activating polypeptide (PACAP) on cAMP formation and growth hormone release from chicken anterior pituitary cells. Annals of the New York Academy of Sciences 865 471-474.

Perez Jurado LA, Phillips JA, III, Summar ML, Mao J, Weber JL, Schaefer FV, Hazan J \& Argente J 1994 Genetic mapping of the human growth hormone-releasing factor gene (GHRF) using two intragenic polymorphisms detected by PCR amplification. Genomics 20 132-134.

Peter RE \& Marchant TA 1995 The endocrinology of growth in carp and related species. Aquaculture 129 299-321.

Radcliff RP, Lookingland KJ, Chapin LT \& Tucker HA 2001 Pituitary adenylate cyclase-activating polypeptide induces secretion of growth hormone in cattle. Domestic Animal Endocrinology 21 187-196.

Sawangjaroen K \& Curlewis JD 1994 Effects of pituitary adenylate cyclaseactivating polypeptide (PACAP) and vasoactive intestinal polypeptide (VIP) on prolactin, luteinizing hormone and growth hormone secretion in the ewe. Journal of Neuroendocrinology 6 549-555.

Sawangjaroen K, Anderson ST \& Curlewis JD 1997 Effects of pituitary adenylate cyclase-activating polypeptide (PACAP) and vasoactive intestinal polypeptide (VIP) on hormone secretion from sheep pituitary cells in vitro. Journal of Neuroendocrinology 9 279-286.

Schagger H \& von Jagow G 1987 Tricine-sodium dodecyl sulfatepolyacrylamide gel electrophoresis for the separation of proteins in the range from 1 to $100 \mathrm{kDa}$. Analytical Biochemistry 166 368-379.

Sherwood NM \& Harvey B 1986 Topical absorption of gonadotropinreleasing hormone $(\mathrm{GnRH})$ in goldfish. General and Comparative Endocrinology 61 13-19.

Sherwood NM \& Wu S 2005 Developmental role of GnRH and PACAP in a zebrafish model. General and Comparative Endocrinology 142 74-80.

Shioda S, Ohtaki H, Nakamachi T, Dohi K, Watanabe J, Nakajo S, Arata S, Kitamura S, Okuda H, Takenoya F et al. 2006 Pleiotropic functions of PACAP in the CNS: neuroprotection and neurodevelopment. Annals of the New York Academy of Sciences 1070 550-560.

Small BC \& Nonneman D 2001 Sequence and expression of a cDNA encoding both pituitary adenylate cyclase activating polypeptide and growth hormone-releasing hormone-like peptide in channel catfish (Ictalurus punctatus). General and Comparative Endocrinology 122 354-363.

Sze KH, Zhou H, Yang Y, He M, Jiang Y \& Wong AO 2007 Pituitary adenylate cyclase-activating polypeptide (PACAP) as a growth hormone (GH)-releasing factor in grass carp: II. Solution structure of a brain-specific PACAP by nuclear magnetic resonance spectroscopy and functional studies on GH release and gene expression. Endocrinology 148 5042-5059.

Tam JK, Lee LT \& Chow BK 2007 PACAP-related peptide (PRP)-molecular evolution and potential functions. Peptides 28 1920-1929.

Vaudry D, Gonzalez BJ, Basille M, Fournier A \& Vaudry H 1999 Neurotrophic activity of pituitary adenylate cyclase-activating polypeptide on rat cerebellar cortex during development. PNAS 96 9415-9420.

Vaudry D, Gonzalez BJ, Basille M, Yon L, Fournier A \& Vaudry H 2000 Pituitary adenylate cyclase-activating polypeptide and its receptors: from structure to functions. Pharmacology Review 52 269-324. 
Vaughan JM, Rivier J, Spiess J, Peng C, Chang JP, Peter RE \& Vale W 1992 Isolation and characterization of hypothalamic growth-hormone releasing factor from common carp, Cyprinus carpio. Neuroendocrinology 56 539-549.

Wong AO, Leung MY, Shea WL, Tse LY, Chang JP \& Chow BK 1998 Hypophysiotropic action of pituitary adenylate cyclase-activating polypeptide (PACAP) in the goldfish: immunohistochemical demonstration of PACAP in the pituitary, PACAP stimulation of growth hormone release from pituitary cells, and molecular cloning of pituitary type I PACAP receptor. Endocrinology 139 3465-3479.

Wong AO, Li W, Leung CY, Huo L \& Zhou H 2005 Pituitary adenylate cyclase-activating polypeptide (PACAP) as a growth hormone (GH)releasing factor in grass carp. I. Functional coupling of cyclic adenosine $3^{\prime}, 5^{\prime}$-monophosphate and $\mathrm{Ca}^{2+} /$ calmodulin-dependent signaling pathways in PACAP-induced GH secretion and $\mathrm{GH}$ gene expression in grass carp pituitary cells. Endocrinology 146 5407-5424.
Xiao D, Chu MM, Lee EK, Lin HR \& Wong AO 2002 Regulation of growth hormone release in common carp pituitary cells by pituitary adenylate cyclase-activating polypeptide: signal transduction involves cAMP- and calcium-dependent mechanisms. Neuroendocrinology 76 325-338.

Yon L, Feuilloley M, Chartrel N, Arimura A, Fournier A \& Vaudry H 1993 Localization, characterization and activity of pituitary adenylate cyclase-activating polypeptide in the frog adrenal gland. Journal of Endocrinology 139 183-194.

Received in final form 26 February 2008

Accepted 20 March 2008

Made available online as an Accepted Preprint 20 March 2008 